\title{
The Effects of Articulated Buses on Dwell and Running Times
}

\author{
Ahmed M. El-Geneidy and Nithya Vijayakumar \\ McGill University
}

\begin{abstract}
Articulated buses are being operated more frequently on popular bus routes, as they can handle higher passenger loads and increase rider comfort. Dwell and running times associated with articulated buses are expected to be different from regular low-floor buses. We use archived bus operation and passenger information from three heavily-used bus routes operated by the Sociéte de Transport de Montréal, Canada, to measure these differences. Operation of articulated buses yielded to savings in dwell time, especially with high levels of passenger activity and the use of the third door in alighting. These savings were not reflected in running time, due to increases in the time associated with acceleration, deceleration, and merging with traffic. This study gives transit planners and operators important information on the differences in operating environments between regular and articulated buses.
\end{abstract}

\section{Introduction}

Articulated buses are being used more frequently on popular bus routes, as they can handle high volume passenger loads. Articulated buses can increase the speed of boarding and alighting at each stop, as well as reduce the number of buses needed on a route. Experts recommend the use of articulated buses as part of bus rapid transit (BRT) systems and express routes (Levinson et al. 2002). It is expected that the use of articulated buses in BRT systems will help attract more choice riders (Pahs et al. 2002). This is related to the expected improvements associated to 
the use of this bus type, which include increases in the levels of comfort to existing users through more space on the bus per passenger and decreased dwell time (time associated to passenger activity) (Hemily and King 2008; Hemily 2008). To our knowledge, these benefits have not been quantified in terms of operational benefits to the transit agency or time savings to transit users. In Fall 2009, the Société de Transport de Montréal (STM), the transit provider on the Island of Montréal, introduced articulated buses on routes 69,121 , and 467 as a measure to improve bus services along these highly used routes. STM's main goal with this action was to increase passenger satisfaction and attract new choice riders by reducing overcrowding along heavily-used routes. This study compares the effects of articulated buses to regular low-floor buses on dwell and running times using archived Automatic Vehicle Location (AVL) and Automatic Passenger Counters (APC) data. It gives transit planners and operators important information on the operating environment of articulated buses. This information can be used to adjust the schedules of bus transit routes where articulated buses operate.

The paper begins with a literature review on the use of articulated buses and its expected effects. The next sections describe the data being used in the analysis and the methodology. These two sections are followed by a discussion of the model results and a conclusion and recommendation section.

\section{Literature Review}

Articulated buses frequently are used in BRT systems and heavily-used routes (Levinson et al. 2002; Jarzab et al. 2002). Articulated buses have an advantage over single-body low-floor buses because they can carry twice as many passengers during one trip (Kaneko et al. 2006). On high-capacity bus routes, articulated buses reduce staff and bus stock necessary to transport passengers (Smith and Hensher 1998). Compared to regular buses, articulated buses have higher loading speeds and can carry a higher passenger capacity (Levinson et al. 2002; Smith and Hensher 1998). In 2008, the Transit Cooperative Research Program (TCRP) published a report on the use of high-capacity buses, including articulated buses. The report provided a synthesis of experiences by different transit agencies in North America. Most transit agencies reported that maintenance cost for high capacity buses was greater than regular buses. Meanwhile, fuel economy and acceleration performance was lower. Passengers enjoyed the additional comfort of larger buses due to more available seating and reductions in crowding. (Hemily and King 2008; Hemily 2008). 
The use of articulated buses is expected to have an effect on dwell and running time. The availability of archived AVL and APC data made it possible for various transit agencies to improve scheduling, develop performance measures, and evaluate various operational strategies (Strathman et al. 2002; Strathman 2002; El-Geneidy et al. 2010; Berkow et al. 2009; Bertini and El-Geneidy 2003; El-Geneidy and Surprenant-Legault 2010). These data were used by various researchers in generating statistical models to understand running time and dwell time (Bertini and El-Geneidy 2004; Dueker et al. 2004; Kimpel et al. 2005).

Dwell time is the time associated to passenger activity at each stop, including door opening and door closing times. Most dwell time analyses attribute increased dwell time to increased passenger activity (Cundil and Watts 1973; Levine and Torng 1994; Vandebona and Richardson 1985). One study looked at the factors affecting dwell time using archived AVL and APC data (Dueker et al. 2004). Dwell time is affected by passenger activity, which door is being used for this activity, the number of passengers paying with cash or change, stop sequence, and time of day (Kraft and Bergen 1974; Levinson 1983). Although the number of passengers using articulated buses is expected to be higher, due to the size of the bus and the nature of the routes being served by this bus type, the use of articulated buses is likely to have a negative effect on dwell time. The amount of time consumed per passenger is expected to decline with the use of articulated buses, due to the presence of a third door for alighting. However, dwells may not be significantly reduced if all boardings occur at the front door to pay a fare (Hemily and King 2008; Hemily 2008). Levinson's (1983) classical study estimated that each passenger boarding and alighting added 2.75 seconds to the constant dwell time of 5 seconds on any bus route. The height of the bus floor is expected to affect dwell time as well. Lowfloor buses can shorten dwells by 13-15 percent (Levine and Torng 1994). Dwell time accounts for 9 to 26 percent of total running time (Levinson 1983). Reducing dwells at bus stations is expected to reduce overall running time and can improve reliability and speed (Levine and Torng 1994).।

Reductions in running time make transit services more attractive to existing and potential users (Levinson 1983; Krizek and El-Geneidy 2007). Levinson (2001) mentions the use of articulated and low-floor buses as the vehicle design of the future. Different-sized buses should be used on varying bus routes; articulated buses should be used on high frequency routes (Levinson 2001) with high levels of demand. However, high frequency routes and high variations in dwell times at each station can also lead to bus bunching (Yabe 2005). Slack often is added 
to improve bus on-time performance, but it adds to travel time (Daganzo 2009). Daganzo (2009) proposed having dynamic holding times based on AVL/APC data and many service points to maintain bus headways. The use of articulated buses on high frequency bus routes should be addressed in scheduling to avoid any decline in on-time performance and reliability of service.

Running time is known as the time that takes a bus to complete a trip between two defined points along a route (Ceder 2007). Shorter running times will make buses a more attractive mode choice. Running time models are used to understand existing transit performance in order to implement new operational strategies or adopt new technologies to improve services (Berkow et al. 2009; Bertini and El-Geneidy 2004; Kimpel et al. 2004). Determinants of running time include trip distance, number of bus stops, passenger boardings and alightings, time of day, weather, congestion, departure delays and nonrecurring events (Abkowitz and Engelstein 1983; Abkowitz and Tozzi 1987; Guenthner and Sinha 1983; Levinson 1983; Strathman et al. 2000; Tétreault and El-Geneidy 2010). The use of articulated buses is expected to have a mixed effect on running time. The first is a negative effect due to the likely decline in dwell times, and the second is a positive effect due to the size of the bus and the time associated to acceleration, deceleration, and merger with regular traffic.

\section{Case Study and Data}

Montréal, Québec, is the second most populous metropolitan area in Canada, with 3.7 million inhabitants. STM operates bus and subway services on the Island of Montréal, which is the home to about half of the region's population. Four subway lines served by 759 cars and 192 bus routes served by 1,600 vehicles comprise the STM network, allowing for over a million trips per weekday. In 2008, STM started a series of improvements to its existing service as part of an overall plan targeting an increase of transit ridership by eight percent in five years. These improvements included increasing service hours along several routes, implementing express (limited stop) service, offering new bus routes, and purchasing low-floor buses with wide doors as well as articulated buses. In fall 2009, the new articulated buses were delivered and operating along three heavily-used bus transit routes on the Island of Montréal (Routes 69, 121, and 467). These routes are shown in Figure 1. The routes had both articulated and regular buses serving them. STM noticed a mixed effect from implementing articulated buses along these routes. These effects included increases in running time along some of the trips operated by articulated buses. 

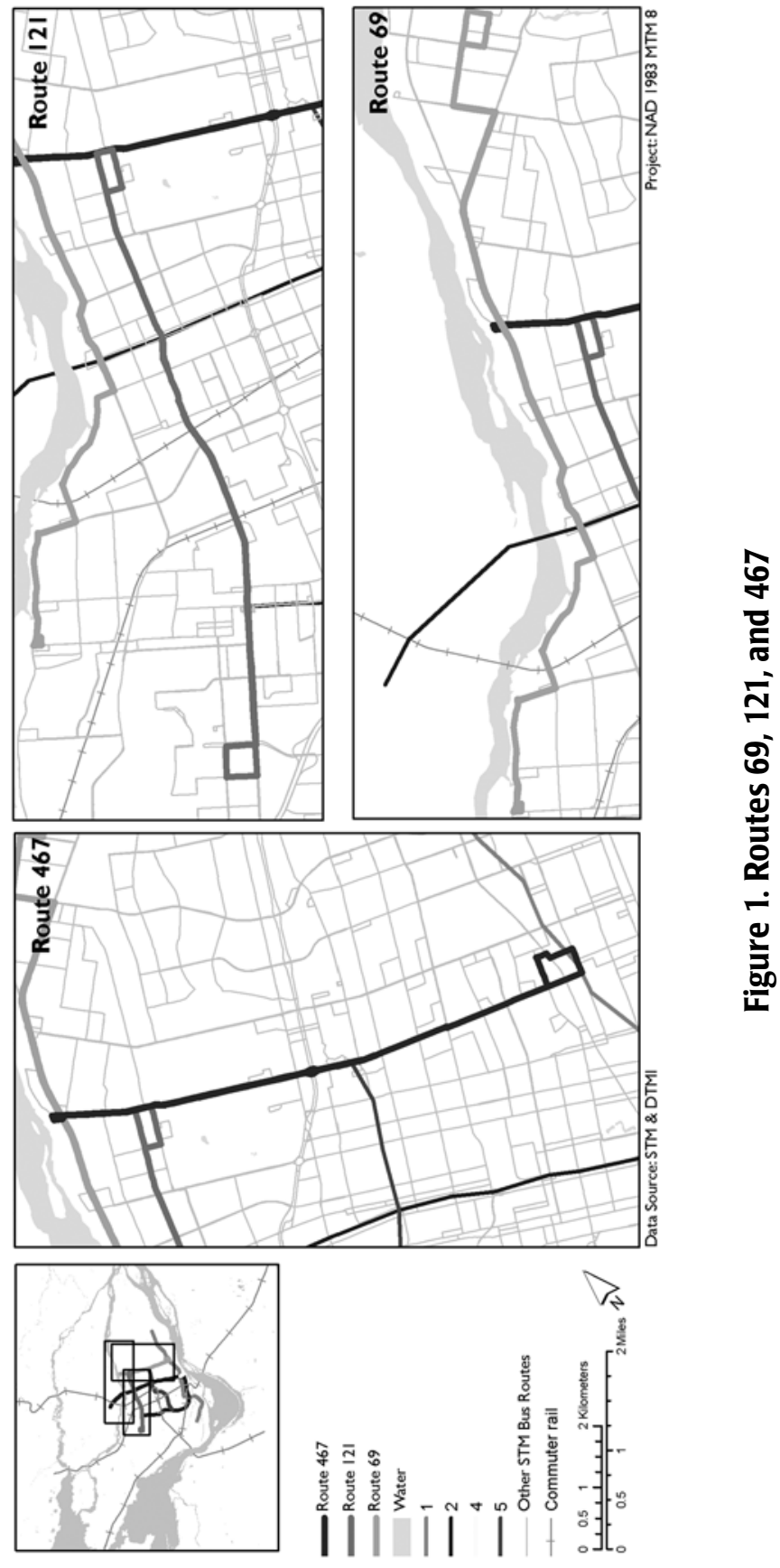
Accordingly, a comprehensive study was needed to understand the effects of articulated buses on transit operations, especially running time, to introduce some modifications to the existing schedules.

Route 69 runs east-west along Boulevard Gouin and Boul. Henri Bourassa; it passes by one métro (subway) station at its midway point, as well as a commuter rail line. Route 121 runs east-west as well, along rue Côte-Vertu and rue Sauvé; and it connects to two métro stations and two commuter rail lines. Route 467 is a limited stop service that runs north-south along Boul. St. Michel parallel to route 67 . Both routes have a combined daily ridership of 42,000 passengers, and 20,000 of them board route 467 . Route 467 connects to two métro stations, one at its southern terminus and another at its midway point. The built form around these routes is mostly three-story triplexes mixed with some commercial buildings near major intersections. Table 1 includes a summary of route characteristics. The daily boarding figures are derived from APC sampling between January and March 2010.

Table 1. Physical characteristics of Routes 69, 121, and 467

\begin{tabular}{|l|c|c|c|c|c|c|}
\hline & \multicolumn{3}{|l|}{ Route 69 } & \multicolumn{2}{l|}{ R121 } & \multicolumn{2}{l|}{ Route 467 } \\
\hline Direction & $\mathrm{E}$ & $\mathrm{W}$ & $\mathrm{E}$ & $\mathrm{W}$ & $\mathrm{N}$ & $\mathrm{S}$ \\
\hline Length $(\mathrm{km})$ & 15.56 & 15.5 & 11.21 & 11.56 & 9.13 & 9.97 \\
\hline Number of stops & 72 & 70 & 49 & 52 & 15 & 16 \\
\hline Daily boardings & \multicolumn{2}{|c|}{28,000} & \multicolumn{2}{c|}{36,000} & \multicolumn{2}{c|}{20,000} \\
\hline Type of service & \multicolumn{2}{|c|}{ Regular } & \multicolumn{2}{c|}{ Regular } & \multicolumn{2}{c|}{ Limited stop } \\
\hline
\end{tabular}

\section{Methodology}

AVL and APC data use is widespread in transit research when changes in a service need to be measured or evaluated (Dueker et al. 2004; El-Geneidy et al. 2006; Kimpel et al. 2004; El-Geneidy and Surprenant-Legault 2010). As only 18 percent of STM's buses are outfitted with AVL and APC systems, STM samples its routes at different moments to obtain a complete picture of its network. The data recorded at both the stop and the trip levels then can be used to adjust schedules or to generate performance measures. AVL and APC data were collected for a sample of trips serving the three bus routes between January 4 and March 15, 2010. The entries from AVL and APC systems include bus arrival and departure times at each stop along the route, as well as passenger activity. A total of 487,588 individual stop 
records was obtained from this sample. These records were cleaned in order to remove incomplete trips, recording errors and layover times.

The objective of this paper is to measure the effects of operating articulated buses on dwell and running times along three bus routes operated by STM. The analysis is conducted at two levels of analysis; the first is the stop level (to measure the effects on dwell time), and the second is the trip level (to measure the effects on running time). Two datasets were generated after the data cleaning process was completed. The first dataset includes every stop with recorded passenger activity and a dwell time greater than five seconds. This dataset contains 253,260 records and will be used in the dwell time analysis. The second dataset is a trip-level data for routes 69,121 , and 467. This dataset includes 9,235 records; 4,350 trips were made using articulated buses, and 4,885 trips were made using regular low-floor buses.

The analysis includes two statistical models. Each model is concerned with a different level of analysis. The first is a dwell time model, while the second is a running time model. Table 2 includes a list of variables included in the dwell time model. It is important to note that the first, last and second to last stops along every route were omitted, due to the presence of longer dwells. This can be related to layovers or early layovers that were observed along certain routes.

The dwell time model measures the effects of a number of variables, including boardings and alighting at each door, stop sequence, and passenger load on dwell time. Dummies are included to control for time of day and route. Weather conditions are represented by the amount of snow cover in centimeters. The main policy variable, which is articulated bus, is included in the statistical model. In addition, an interaction variable is included, which is the total number of people alighting from a bus at a stop multiplied by the articulated dummy. This variable captures the effects of alightings from articulated buses on the dwell time. All the regular and articulated buses used are low-floor buses; accordingly, a low-floor dummy was excluded from this model.

In this model, it is expected that passenger activity will have a positive effect on dwell time. The square term is expected to be negative and statistically significant. This negative sign associated with positive sign from the passenger activity variables indicates that the amount of time used by each additional passenger will be less than the time associated with passenger alighting or boarding before him (Berkow et al. 2009). The passenger activity is separated by a door to enable isolation of the effects of the third door. Alighting along door 3 is expected to be statistically significant with the lowest coefficients compared to the other two 


\section{Table 2. Stop-Level Analysis Variables}

\begin{tabular}{|c|c|}
\hline Variable Name & Description \\
\hline Dwell Time & $\begin{array}{l}\text { The time in seconds from when a bus arrives at a bus stop and leaves a } \\
\text { bus stop. }\end{array}$ \\
\hline Board1 & Total number of passengers that boarded at door 1 at a single bus stop. \\
\hline Board1^2 & $\begin{array}{l}\text { The square of the total number of passengers that board at door } 1 \text { at a } \\
\text { single bus stop. }\end{array}$ \\
\hline Alight 1 & Total number of passengers that alighted at door 1 at a single bus stop. \\
\hline Alight1^2 & $\begin{array}{l}\text { The square of the total number of passengers that alighted at door } 1 \text { at a } \\
\text { single bus stop. }\end{array}$ \\
\hline Board2 & Total number of passengers that boarded at door 2 during a single trip. \\
\hline Board2^2 & $\begin{array}{l}\text { The square of the total number of passengers that boarded at door } 2 \text { dur- } \\
\text { ing a single trip. }\end{array}$ \\
\hline Alight2 & Total number of passengers that alighted at door 2 during a single trip. \\
\hline Alight2^2 & $\begin{array}{l}\text { The square of the total number of passengers that alighted at door } 2 \text { dur- } \\
\text { ing a single trip. }\end{array}$ \\
\hline Board3 & Total number of passengers that boarded at door 3 during a single trip. \\
\hline Board3^2 & $\begin{array}{l}\text { The square of the total number of passengers that board at door } 3 \text { during } \\
\text { a single trip. }\end{array}$ \\
\hline Alight3 & Total number of passengers that alighted at door 3 during a single trip. \\
\hline Alight3^2 & $\begin{array}{l}\text { The square of the total number of passengers that alighted at door } 3 \text { dur- } \\
\text { ing a single trip. }\end{array}$ \\
\hline AM Peak & $\begin{array}{l}\text { A dummy variable that is equal to } 1 \text { if the trip took place between } 6: 30 \mathrm{am} \\
\text { and 9:30am. }\end{array}$ \\
\hline PM Peak & $\begin{array}{l}\text { A dummy variable that is equal to } 1 \text { if the trip took place between } 3: 30 \mathrm{pm} \\
\text { and } 6: 30 \mathrm{pm} \text {. }\end{array}$ \\
\hline Midday & $\begin{array}{l}\text { A dummy variable that is equal to } 1 \text { if the trip took place between 9:30am } \\
\text { and 3:30 pm. }\end{array}$ \\
\hline Articulated & A dummy variable that is equal to 1 if the bus is articulated. \\
\hline R121 & A dummy variable equal to one if the trip was made on bus route 121. \\
\hline R467 & A dummy variable equal to one if the trip was made on bus route 467 . \\
\hline Passenger Load & The total number of passengers on a bus. \\
\hline Snow Cover & The amount of snow on the ground in centimeters on the day of the trip. \\
\hline Alight Interaction & $\begin{array}{l}\text { The total number of passengers alighting at a single station on an articu- } \\
\text { lated bus. }\end{array}$ \\
\hline Board Interaction & $\begin{array}{l}\text { The total number of passengers boarding at a single station on an articu- } \\
\text { lated bus. }\end{array}$ \\
\hline
\end{tabular}


doors. Meanwhile, boardings from door 1 are expected to increase dwell time the most compared to the other doors. This is due to fare-box transactions. STM uses a smart card system that requires every passenger to attach his monthly pass or tickets to a reader for a couple of seconds. Boardings from the second and third doors are rare and occur only when buses are full and do not require fare collection. Since passengers normally board from door 1 , boardings on articulated buses are not expected to decrease dwell times; however, alighting from articulated buses should be statistically significant and shorten dwell time. The interaction variable will show the influence of each passenger alighting from an articulated bus on dwell time. It is expected that this variable will have a statistically significant negative effect on dwell time. The articulated bus variable is expected to shorten dwell time; however, since we do control for the alightings through the interaction dummy, this effect might change in the model. Route 467 is expected to be slower in terms of dwell time since each stop along this route is a time point (the route is a limited stop service) and the schedule of this route was not adjusted after the implementation of the service. So buses are generally holding at stops when they arrive early. Doors usually are closed if a bus is holding at a stop, thus the hold is not included in the dwell time analysis so as not to skew the results. Regarding passenger loads, it is expected that higher loads will lead to shorter dwells. This expectation is derived from previous research concentrating on dwell time (Dueker et al. 2004). Finally, the amount of snow on the ground is expected to increase the amount of time associated to dwell time. This is due to the presence of slippery sidewalks that requires more caution from passengers.

The second part of the analysis includes a run time model. This model is generated at the trip level. The trip-level analysis excludes data from the first and last stops in both directions to avoid the effects of layover time (Berkow et al. 2009). It was noticed through a detailed analysis of the studied routes that some drivers take their layovers at the stop before the last. Consequently, the trip is defined as departure from the first stop to departure from the third stop before the last. Passenger activity from the first and last stop and before the last stop were excluded because of higher risk of error for this variable due to a layover.

A number of factors have an influence on running time. These can be divided into factors that do not fall under the control of the transit agency, such as congestion or weather, and those that can be controlled by the agency, such as route design and the driver behavior (Strathman and Hopper 1993). Nevertheless, operators still can account for uncontrollable factors through scheduling and "real-time cor- 
rective actions" (Strathman and Hopper 1993). The factors affecting running time include trip distance, passenger activity, number of stops made, period of the day, driver characteristics, delay at the beginning of a trip, weather conditions, bus type (articulated or low-floor) and congestion (Abkowitz and Engelstein 1983; Abkowitz and Tozzi 1987; Guenthner and Sinha 1983; Strathman et al. 2000; Levinson 1983; Strathman and Hopper 1993; El-Geneidy and Surprenant-Legault 2010). Table 3 lists the variables used in this analysis.

In this model, running time is expected to increase with distance, passenger activity, peak hour trips, delay at the beginning at the trip, and adverse weather conditions, which is measured by the amount of snow on the ground. Trips running along Route 467 are expected to be faster than the other routes since this is a limited stop service route. Attributes of articulated buses are expected to have mixed effects on running times. The third door that allows the passenger activity to be faster will reduce running time. Acceleration, deceleration, and merger time are expected to consume more time for articulated buses relative to regular buses, thus contributing to a longer running time (Hemily and King 2008; Hemily 2008). Accordingly, an interaction variable is added to the model. This variable is expected to show that articulated buses decrease overall running time. Meanwhile, the articulated dummy is expected to increase running time due to the effects of acceleration and deceleration. During the AM peak and the PM peak, Route 467 is operated along an exclusive bus way. Accordingly, isolating the effect of the exclusive bus way is a must, which is done through two dummy variables. In previous research, snow cover has shown to be a variable that lengthens running time (Tétreault and ElGeneidy 2010). This variable is included to the model to control for adverse weather conditions and its effects on the operating environment.

\section{Analysis}

Table 4 includes summary statistics for the stop level data used in the dwell time model. The average dwells were 24.44 seconds for articulated buses and $24.41 \mathrm{sec}-$ onds for regular buses. This shows a minor difference in terms of the amount of time associated to dwells. The articulated buses have a lower standard deviation, indicating less variance when compared to the regular buses. This is a key reliability factor, making the predictability of dwell time for articulated buses higher than regular buses. The average loads and passenger activity on an articulated bus were higher; the average load on an articulated bus was 24.89 passengers, while the average load on a regular bus was 22.48 passengers. It is clear that the difference 
Table 3. Running Time Analysis Variables

\begin{tabular}{|c|c|}
\hline Variables & Descriptions \\
\hline Running time & $\begin{array}{l}\text { The running time per trip in seconds, from the departure of the first stop } \\
\text { before the designated trip to the departure from the last stop of the } \\
\text { designated trip or segment. }\end{array}$ \\
\hline Distance & The length of the studied route in kilometers. \\
\hline Articulated & $\begin{array}{l}\text { A dummy variable that equals to one if the trip observed is recorded uses } \\
\text { an articulated bus. }\end{array}$ \\
\hline Total Boardings & The sum of boardings for each trip. \\
\hline Total Alightings & The sum of alightings for each trip. \\
\hline R121 & Dummy variable that equals to 1 if the trip observed is serving Route 121. \\
\hline R467 & Dummy variable that equals to 1 if the trip observed is serving Route 121. \\
\hline $\begin{array}{l}\text { Actual stops } \\
\text { made }\end{array}$ & The number of actual stops that was actually made by the bus. \\
\hline Delay Start & $\begin{array}{l}\text { The delay at the start of the route in seconds (leave time - scheduled } \\
\text { time). }\end{array}$ \\
\hline AM Peak & A dummy variable for trips that took place between $6: 30 \mathrm{am}$ to $9: 30 \mathrm{am}$. \\
\hline PM Peak & A dummy variable for trips that took place between $3: 30 \mathrm{pm}$ and $6: 30 \mathrm{pm}$. \\
\hline Midday & A dummy variable for trips that took place between 9:30am and 3:30pm \\
\hline AM Peak R467 & $\begin{array}{l}\text { A dummy variable for trips along Route } 467 \text { that used the exclusive bus } \\
\text { way in AM peak. }\end{array}$ \\
\hline PM Peak R467 & $\begin{array}{l}\text { A dummy variable for trips along route } 467 \text { that used the exclusive bus } \\
\text { way in PM peak. }\end{array}$ \\
\hline Alight Interaction & The total number of alightings on an articulated bus during a trip. \\
\hline Board Interaction & The total number of boarding on an articulated bus during a trip. \\
\hline \multirow[t]{2}{*}{ Snow Cover } & The amount of snow on the ground in centimeters. \\
\hline & A dummy variable equal to one if the trip was made on bus route 121. \\
\hline R467 & A dummy variable equal to one if the trip was made on bus route 467 . \\
\hline Passenger Load & The total number of passengers on a bus. \\
\hline Snow Cover & The amount of snow on the ground in centimeters on the day of the trip. \\
\hline Alight Interaction & $\begin{array}{l}\text { The total number of passengers alighting at a single station on an articu- } \\
\text { lated bus. }\end{array}$ \\
\hline Board Interaction & $\begin{array}{l}\text { The total number of passengers boarding at a single station on an articu- } \\
\text { lated bus. }\end{array}$ \\
\hline
\end{tabular}


in the number of boardings is minor between articulated and regular buses. The main advantage of using articulated buses is highlighted in the mean and standard deviation values associated to number of people alighting the bus from door 1 and door 2. This value was 1.29 for alighting from door 1 and 1.61 from door 2 for regular buses and 1.05 and 1.02 for articulated buses. Alighting on articulated buses is split between 3 doors, instead of just two, which interferes less with boarding from door 1 .

Table 4. Summary Statistics at the Stop Level

\begin{tabular}{|l|c|c|c|c|}
\hline \multirow{2}{*}{} & \multicolumn{2}{|c|}{ Articulated Buses } & \multicolumn{2}{c|}{ Regular Buses } \\
\cline { 2 - 5 } & Mean & Std. Deviation & Mean & Std. Deviation \\
\hline Dwell Time & 24.44 & 27.24 & 24.41 & 29.23 \\
\hline Board1 & 2.84 & 4.98 & 2.82 & 4.97 \\
\hline Alight1 & 1.05 & 1.63 & 1.29 & 2.06 \\
\hline Board2 & 0.002 & 0.08 & 0.01 & 0.15 \\
\hline Alight2 & 1.02 & 2.15 & 1.61 & 3.22 \\
\hline Board3 & 0.002 & 0.07 & $\ldots$ & $\ldots$ \\
\hline Alight3 & 0.82 & 2.02 & $\ldots$ & $\ldots$ \\
\hline Passenger Load & 24.89 & 14.92 & 22.48 & 13.48 \\
\hline Number of Observations & \multicolumn{2}{|c|}{123,859} & & 129,401 \\
\hline
\end{tabular}

For the running time, Table 5 includes a summary statistics of the key variables aggregated at the trip level of analysis. The mean running time for trips using articulated buses was around 45.2 minutes, while for the regular buses it was around $43 \mathrm{~min}$ utes. This average leads to a difference of 2.2 minutes per trip. Observing the mean values, we can say that articulated buses are slower by around 2.2 minutes, on average, compared to regular buses. In addition, the standard deviation of running time for articulated buses is much higher than standard deviation of regular buses. The observation noticed in the decline in dwells is not reflected in the running time. This confirms the increase in running time that STM noticed along some trips operated by the articulated buses, but not for all trips. Total boardings and total alightings have increased along articulated buses, which were expected due to the added capacity. The increase was accompanied with increase in variation as well. Another variable that explains the increase in the variation of running time is the increase in the number of actual stops made. Finally, delay at start for articulated buses was much higher 11.53 seconds compared to 6.2 seconds for regular buses. 
Table 5. Summary Statistics at the Trip Level

\begin{tabular}{|l|c|c|c|c|}
\hline \multirow{2}{*}{} & \multicolumn{2}{|c|}{ Articulated Buses } & \multicolumn{2}{c|}{ Regular Buses } \\
\cline { 2 - 5 } & Mean & Std. Deviation & Mean & Std. Deviation \\
\hline Running Time in Seconds & $2,712.43$ & 647.88 & $2,580.85$ & 592.28 \\
\hline Total Boardings & 85.24 & 39.90 & 79.83 & 37.58 \\
\hline Total Alightings & 85.95 & 38.92 & 80.77 & 37.11 \\
\hline Actual Stops Made & 32.49 & 13.32 & 30.54 & 12.05 \\
\hline Delay Start & 11.53 & 71.68 & 6.20 & 60.35 \\
\hline Number of Observations & \multicolumn{3}{|c|}{4,350} & \multicolumn{3}{c|}{4,885} \\
\hline
\end{tabular}

To better understand the findings from Tables 4 and 5 , a more detailed analysis of dwell and running times can help identifying determinants of time savings and observed changes. The following section includes dwell time as well as running time models.

\section{Dwells and Running Time Models}

A linear regression model is developed using dwell time in seconds as the dependent variable. Table 6 presents the results of the model. The t-statistics and the statistical significance are reported in the table along with the coefficients. This model explains 51 percent of the variation in dwell time.

For the first person that boards at door 1, 4.6 seconds is added dwell time, but each additional person boarding at the first door will take 0.027 seconds less time. The more people that board a bus, the less time it takes per passenger to board. Boarding at the second and third doors only adds 2.19 and 2.33 seconds, respectively, to the model. It takes far less time to board at the second and third doors, because passengers do not need to scan their cards. Alighting at the first door adds 2.74 seconds, alighting at the second door adds 1.65 seconds, and alighting at the third door adds 1.01 seconds to dwell time. It is clear that the use of the third door leads to a decline in the contribution of each passenger alighting to the total dwell time. Policies encouraging the use of a third door for alighting should be emphasized to increase the benefits of using articulated buses. For all the squared values for boarding and alighting, each additional passenger adds less time to overall dwell time compared to the passenger ahead of him. 
Table 6. Dwell Time Model

\begin{tabular}{|c|c|c|c|}
\hline Variable Name & Coefficient & t-stat & Stat. Sig. \\
\hline Board1 & 4.05 & 206.20 & 0.00 \\
\hline Board1^2 & -0.02 & -47.60 & 0.00 \\
\hline Alight 1 & 2.73 & 59.97 & 0.00 \\
\hline Alight1^2 & -0.07 & -15.82 & 0.00 \\
\hline Board2 & 2.19 & 5.17 & 0.00 \\
\hline Board2^2 & -0.11 & -2.35 & 0.01 \\
\hline Alight2 & 1.65 & 47.78 & 0.00 \\
\hline Alight2^2 & -0.05 & -30.96 & 0.00 \\
\hline Board3 & 2.33 & 1.81 & 0.07 \\
\hline Board3^2 & -0.21 & -1.34 & 0.18 \\
\hline Alight3 & 1.00 & 13.03 & 0.00 \\
\hline Alight3^2 & -0.06 & -15.68 & 0.00 \\
\hline AM Peak & -1.37 & -10.56 & 0.00 \\
\hline PM Peak & -0.47 & -3.71 & 0.00 \\
\hline Midday & 0.24 & 2.15 & 0.03 \\
\hline Articulated & 1.22 & 11.31 & 0.00 \\
\hline R121 & 0.61 & 6.01 & 0.00 \\
\hline R467 & 6.85 & 46.96 & 0.00 \\
\hline Passenger Load & -0.12 & -40.60 & 0.00 \\
\hline Snow Cover & 0.02 & 1.78 & 0.07 \\
\hline *Alight Interaction & -0.16 & -5.54 & 0.00 \\
\hline **Board Interaction & 0.28 & 14.87 & 0.00 \\
\hline Constant & 10.89 & 69.72 & 0.00 \\
\hline R Square & 0.51 & & \\
\hline $\mathbf{N}$ & 253,260 & & \\
\hline \multicolumn{3}{|c|}{ Dependent Variable Dwell Time in Seconds } & \\
\hline
\end{tabular}

* Alight Interaction $=$ Total Alightings * Articulated dummy

** Board Interaction = Total Boardings * Articulated dummy

Dwells taking place during the morning and afternoon peak hours are generally faster compared to late evening and early morning dwells. A trip during the morning peak takes 1.31 seconds less, while trips during the evening peak take 0.4 seconds less compared to late evening and early morning dwells. These lower 
dwells have been attributed to more routine passengers and directional traffic during morning routes (Dueker et al. 2004). A bus serving Route 121 consumes 0.6 seconds more per dwell compared to Route 69 . However, dwell time is 6.8 seconds more on Route 467, compared to Route 69 . This is because Route 467 is an express route and has 15 stops, but the schedule has not been changed since Route 467 was implemented and an exclusive bus-way was introduced. Drivers have excess time in the schedules, leaving more time at every stop. Moreover, the drivers have pressure to stay on schedule, compared to the other routes. An interesting finding is that increasing passenger loads lead to decreases in dwell times. This can be related to riders' behavior and their reaction to overcrowded buses. Previous research indicated a similar relationship with higher loads (Dueker et al. 2004). Snow on the ground showed statistical significance, but added only 0.02 seconds to dwells.

An articulated bus adds 1.22 seconds to the dwell time. However, the interaction variable, which looks at passenger alighting on an articulated bus, reveals that increased alighting on an articulated bus, compared to a regular bus, actually reduces dwell time by 0.15 seconds per passenger. Finally, the boarding interaction variable shows a positive and statistically significant effect on dwell time, which means that boarding on articulated buses increases dwell time. Accordingly, the articulated buses cause both increases and decreases in running time, which was hypothesized earlier. It is necessary to have a more precise estimate of the additional time required by articulated buses to run a complete route. This estimate should be used to adjust schedules in order to address the net effect of using articulated buses. Table 7 shows the output of a linear regression model using running time as the dependent variable.

This model explains 92 percent of the variation in running time. This high value is attributed mainly to the inclusion of the distance variable. For every meter in the route length, running time is expected to increase by 0.14 seconds, keeping all other variables at their mean values. This coefficient indicates an average speed of $25 \mathrm{~km} / \mathrm{h}$.

An articulated bus adds an additional 27.2 seconds to the total running time. This addition will require modification to the existing schedules to avoid delays and ontime performance problems. Each boarding adds 1.91 seconds and each alighting adds 1.04 seconds to the total running time while keeping all other variables at their mean values. Boarding on an articulated bus, which is represented by the Board Interaction variable, adds 0.81 seconds to running time. The Alight Interaction variable, which shows alighting activity on articulated buses, demonstrates that 
Table 7. Running Time Model

\begin{tabular}{|l|c|c|c|}
\hline Variable Name & Coefficient & t-stat & Stat. Sig. \\
\hline Distance & 0.14 & 15.69 & 0.00 \\
\hline Articulated & 27.22 & 3.09 & 0.00 \\
\hline Total Boardings & 1.91 & 8.45 & 0.00 \\
\hline Total Alightings & 1.04 & 4.42 & 0.00 \\
\hline R121 & 70.81 & 1.89 & 0.06 \\
\hline R467 & -305.34 & -5.60 & 0.00 \\
\hline Actual Stops Made & 8.30 & 19.13 & 0.00 \\
\hline Delay Start & -0.36 & -13.18 & 0.00 \\
\hline AM Peak & 142.34 & 22.15 & 0.00 \\
\hline PM Peak & 307.69 & 46.92 & 0.00 \\
\hline Midday & 202.57 & 36.43 & 0.00 \\
\hline Alight Interaction & -0.58 & -2.03 & 0.04 \\
\hline Board Interaction & 0.81 & 2.91 & 0.00 \\
\hline AM Peak R467 & 160.03 & 13.02 & 0.00 \\
\hline PM Peak R467 & -66.69 & -6.24 & 0.00 \\
\hline Snow Cover & 2.90 & 4.94 & 0.00 \\
\hline Constant & 217.25 & 1.55 & 0.12 \\
\hline R square & & & \\
\hline N & & 9.9235 & \\
\hline
\end{tabular}

${ }^{*}$ Alight Interaction $=$ Total Alightings * Articulated dummy

** Board Interaction = Total Boardings * Articulated dummy

running time is reduced by 0.81 seconds for every passenger that alights from an articulated bus. Route 121 is faster than route 69 by 70 seconds per trip. Meanwhile, Route 467 is faster by 306 seconds relative to route 67 . This is due to the nature of Route 467 as an express route. During the morning peak, Route 467 has its own exclusive bus-way, yet buses operating along this route during this period of time are slower by 160 seconds. On the other hand, the exclusive bus-way decreases running time by 66 seconds. This can be due to the difference in the levels of congestion during both periods. In addition, for every stop made along the studied routes, 8.30 seconds are added to the running time, which can be attributed to accelerating and decelerating at each stop. For every second of delay at the beginning of a trip running time is expected to decrease by 0.36 seconds. This indicates a recovery of 36 percent of delay by drivers during the trip. This finding is consistent 
with previous studies (El-Geneidy and Surprenant-Legault 2010; Tétreault and ElGeneidy 2010). In addition, morning peak trips are longer by 142 seconds, evening trips are longer by 307 seconds, while midday trips are slower by 202 seconds relative to early am and late evening trips. Finally, for every centimeter of snow on the ground, running time is expected to increase by 2.9 seconds per trip.

It is clear that the effects of operating an articulated bus on dwell and running times are complicated and cannot be isolated using a single variable. In order to understand these effects, a sensitivity analysis is introduced in the following section. This sensitivity analysis depends on multiplying the coefficients by the mean values to obtain the dwell and running times under various scenarios and conditions.

\section{Sensitivity Analysis}

The dwells for each scenario is estimated based on the model presented in Table 6 . The scenarios for the dwell time estimates are presented in Table 8. Each simulation has a constant passenger load of 30 passengers. The estimate also is constructed for morning peak on Route 69 . In the first scenario, the total passenger activity equals 20 passengers. These passengers are distributed as 5 boarding and 15 alighting. Distributing the 15 alighting among the three doors in articulated buses compared to two doors in the regular bus leads to 1.9 percent time saving. Meanwhile, passenger activity of 30 passengers at a stop leads to 4.5 percent of savings in dwell time when utilizing an articulated bus relative to a regular low-floor bus.

\section{Table 8. Simulation of Dwell Gime at a Stop on Route 67 during AM Peak Hours}

\begin{tabular}{|l|c|c|c|c|}
\hline \multirow{2}{*}{ Variable Name } & \multicolumn{2}{|c|}{ 20 Passengers } & \multicolumn{2}{c|}{ 30 Passengers } \\
\cline { 2 - 5 } & Articulated & Regular & Articulated & Regular \\
\hline Boarding Door 1 & 5 & 5 & 5 & 5 \\
\hline Alighting Door 1 & 8 & 8 & 10 & 15 \\
\hline Boarding Door 2 & & & & 10 \\
\hline Alighting Door 2 & 3 & 7 & 10 & 10 \\
\hline Boarding Door 3 & & & & 5 \\
\hline Alighting Door 3 & 4 & & 30 & 30 \\
\hline Passenger Load & 30 & 30 & 58.6 & 61.37 \\
\hline Dwell Time in Seconds & 50.55 & 51.53 & & 4.5 \\
\hline Percentage of Savings & & & & \\
\hline
\end{tabular}


For each simulation, the number of passenger boarding and alighting at each door, boarding and alighting squared, the passenger load and stop sequence are multiplied by the coefficients from Table 6 to calculate the total dwell time per trip. The results indicate that articulated buses save more time per stop, especially with high levels of passenger activity.

The running time simulation uses the model presented in Table 7 to estimate the total travel time for one trip along Route 121 during the morning peak. The passenger load, actual stops, and passenger activity remain constant for each example. Meanwhile, the distance traveled is $11.21 \mathrm{~km}$, which is the actual length of Route 121. The simulation results are presented in Table 9 . It takes an articulated bus 39.3 seconds longer to complete a trip with 120 passengers boarding and alighting, compared to a regular bus. This is while having 30 passengers on board on average, serving 30 stops along the route, and starting 8 seconds late.

Table 9. Simulation of Running Time on Route 121 during AM Peak Hours

\begin{tabular}{|c|c|c|c|c|}
\hline \multirow[b]{2}{*}{ Variable Name } & \multicolumn{2}{|c|}{120 Passengers } & \multicolumn{2}{|c|}{80 Passengers } \\
\hline & Articulated & Regular & Articulated & Regular \\
\hline Total Boarding & 120 & 120 & 60 & 60 \\
\hline Total Alighting & 120 & 120 & 60 & 60 \\
\hline Mean Passenger Load & 25 & 25 & 25 & 25 \\
\hline Number of Actual Stops & 30 & 30 & 30 & 30 \\
\hline Delay at Start & 8 & 8 & 8 & 8 \\
\hline Total Travel Time in Minutes & 44.7 & 43.82 & 41.56 & 40.87 \\
\hline Difference in Seconds & \multicolumn{2}{|c|}{39.00} & \multicolumn{2}{|c|}{41.2} \\
\hline
\end{tabular}

The second scenario uses 60 passengers as the input for passenger activity. Again, the articulated bus is slower by 41.26 seconds. Observing Tables 8 and 9 clearly indicates that articulated buses do save time at the stop level of analysis, yet the savings vanish when measured at the trip level. This can be attributed mainly to acceleration and deceleration time associated to articulated buses. Also, it can be related to the time an articulated bus consumes to merge back with traffic. This difference decreases with the increase in the total number of passengers using the articulated buses. In conclusion, adopting the use of articulated buses requires modifications in the existing schedules to address the additional time needed for operation to avoid delays and on-time performance issues, especially if the articulated buses are introduced along routes with medium levels of passenger activity per trip. The estimated numbers in this scenario are developed at the mean value. 
Since schedules are written to accommodate 95 percent of all trips, adjustments need to be made to these estimations.

Building the relationship between the 95th percentile of running time and the estimated running time in the above scenario, it is estimated that two additional minutes need to be added to the scheduled running time. These two minutes need to be added to each trip serving the above route, if STM chose to keep operating articulated buses along this route at the same level of service. The TCRP report cited that one of the agencies in their study needed to a lot more time for articulated buses due to their slower acceleration (Hemily and King 2008; Hemily 2008). An addition of two minutes per trip will require major modifications in schedules as well as addition of new trips. Using Vuchic's (2005) model for estimating fleet size for a bus transit route with a uniform headway ( 5 minutes) and a constant travel cycle (120 minutes), it is estimated that 24 buses will be needed to operate this route, while an additional bus is needed if articulated buses will be operated along this route to maintain the same level of service. This calculation can be done for different time periods with varying headways to determine the added operational costs of using articulated buses. A different option is to adjust the schedules through increasing the existing headways and using fewer buses. This solution is expected to have an increase in passenger waiting time. TCRP reports on transit agencies implementing measures improve dwell times of articulated buses. These measures include operating articulated buses exclusively on a route to simplify scheduling and developing new fare collection procedures. The fare collection procedures included allowing passengers to use all three doors for boarding in order to take full advantage of increased passenger flow that articulated buses can facilitate(Hemily and King 2008; Hemily 2008).

Finally, another alternative is work on the mechanics of the articulated buses to decrease acceleration and deceleration time through adjustment in transmission systems of articulated buses. STM currently is conducting mechanical studies to measure the differences in acceleration and deceleration time between articulated and regular buses. Various mechanical changes are being tested to the transmission of both types of buses to account for some of these differences in travel time. 


\section{Conclusion}

The objective of this research was to measure the effects of operating articulated buses along three bus routes operated by STM in Montréal Canada. The effects of using articulated buses was measured at two levels: the stop level and the trip level. The stop level analysis concentrated mainly on dwell time saving. It was clear that articulated buses do have a mixed effect on dwell time, yet overall, articulated buses decrease the amount of time associated per passenger alighting leading to major time saving at the stop level. These savings are maximized with higher levels of passenger activity ( $4.5 \%$ savings for 30 passengers). Meanwhile, articulated buses do cause delays at the trip level. So the amount of savings associated to passenger activity is offset by the loss in acceleration, deceleration, and time consumed to merge back in the regular traffic. Articulated buses impose an additional two minutes of delay on the existing schedule of the studied routes. To maintain the existing headway, these two minutes need to be added to the schedules. Accordingly, more buses are needed to operate the existing system with articulated buses while keeping the same level of service. STM has achieved one of its main targets through operating the articulated buses. The increase in the number of boardings on articulated buses compared to regular buses was around 5 passengers per trip. Although this number is small, the studied routes suffered from overcrowding. The use of articulated buses has lead to an increase in the level of comfort and has helped in attracting five new passengers per trip.

STM currently is implementing some tests for mechanical modifications in the transmission system of articulated buses. These modifications are expected to improve the speed of articulated buses. Driver experience plays a big role in running time and bus operations. A detailed study concentrating on differences in driver behavior is recommended to measure to what extent driver fear of collision or comfort in operating articulated buses is recommended. Such study will require simulator systems and on-board driver behavior monitoring systems.

Since the data obtained from the STM was collected from a sample of trips, it was not possible to measure the effects of using articulated service on either the reliability of service or on headways. It was clear that variation in dwell time declined while variation in running time increased. The use of articulated buses is expected to increase the level of bus bunching, which is noticed from the increase in the level of variation in running time. A headway variability analysis is recommended using actual headwaysTo do so, the entire fleet serving these routes will need to 
have AVL and APC systems, which is something that STM is trying to achieve in the next few years.

\section{Acknowledgments}

We would like to acknowledge the Société de Transport de Montréal (STM) for providing the funding and data for this project, especially Michel Tremblay, Jocelyn Grondines, and Sébastien Gagné for their feedback and support during this project.

\section{References}

Abkowitz, M., and I. Engelstein. 1983. Factors affecting running time on transit routes. Transportation Research Part A 17(2): 107-113.

Abkowitz, M., and J. Tozzi. 1987. Research contributing to managing transit service reliability. Journal of Advanced Transportation 21 (Spring): 47-65.

Berkow, M., A. El-Geneidy, and R. Bertini. 2009. Beyond generating transit performance measures: Visualizations and statistical analysis using historical data. Transportation Research Record (2111): 158-168.

Berkow, M., A. El-Geneidy, and R. Bertini. 2009. Beyond generating transit performance measures: Visualizations and statistical analysis using historical data. Paper read at Transportation Research Board 88th Annual Meeting, Washington, D.C.

Bertini, R., and A. El-Geneidy. 2003. Using archived data to generate transit performance measures. Transportation Research Record 1841: 109-119.

Bertini, R., and A. El-Geneidy. 2004. Modeling schedule recovery processes in transit operations for bus arrival time prediction. Journal of Transportation Engineering 130(1): 56-67.

Ceder, A. 2007. Public Transit Planning and Operation, Theory, Modeling And Practice. Burlington, MA: Elsevier Ltd.

Cundil, M., and P. Watts. 1973. Bus boarding and alighting times. In TRRL Rep. LR 521. Crownthorne, U. K.: Transport and Road Research Laboratory.

Daganzo, C. 2009. A headway-based approach to eliminate bus bunching: Systematic analysis and comparisons. Transportation Research Part B 43(10): 913-921. 
Dueker, K. J., T. J. Kimpel, J. G. Strathman, and S. Callas. 2004. Determinants of bus dwell time. Journal of Public Transportation 7(1): 21-40.

El-Geneidy, A., J. Horning, and K. Krizek. 2010. Analyzing transit service reliability using detailed data from automatic vehicular locator system. Journal of Advanced Transportation 44 (4): 1-14.

El-Geneidy, A., J. Strathman, T. Kimpel, and D. Crout. 2006. The effects of bus stop consolidation on passenger activity and transit operations. Transportation Research Record 1971: 32-41.

El-Geneidy, A., and J. Surprenant-Legault. 2010. Limited-stop bus service: An evaluation of an implementation strategy. Paper read at Transportation Research Board 89th Annual Meeting, Washington, D.C.

Guenthner, R. P., and K. C. Sinha. 1983. Modeling bus delays due to passengers boardings and alightings. Transportation Research Record 915: 7-13.

Hemily, B. and King, R. 2008. Uses of higher capacity buses in transit service: A synthesis of transit practice. Washington, D.C.: Transportation Research Board.

Jarzab, J., J. Lightbody, and E. Maeda. 2002. Characteristics of bus rapid transit projects: An overview. Journal of Public Transportation 5(2): 31-46.

Kaneko, T., H. liuzuka, and I. Kageyama. 2006. Steering control for advanced guideway bus system with all-wheel steering system. Vehicle System Dynamics 44: 741-749.

Kimpel, T., J. Strathman, R. Bertini, P. Bender, and S. Callas. 2004. Analysis of transit signal priority using archived TriMet bus dispatch system data. Paper read at 84th Transportation Research Board Annual Meeting, Washington, D.C.

Kimpel, T., J. Strathman, R. Bertini, P. Bender, and S. Callas. 2005. Analysis of transit signal priority using archived TriMet bus dispatch system data. Transportation Research Record 1925: 156-166.

Kraft, W., and T. Bergen. 1974. Evalutation of passenger service-time distribution. Transportation Research Record 505: 13-20.

Krizek, K., and A. El-Geneidy. 2007. Segmenting preferences and habits of transit users and non-users. Journal of Public Transportation 10(3): 71-94.

Levine, J., and G. Torng. 1994. Dwell time effects of low-floor bus design. Journal of Transportation Engineering 120(6): 914-829. 
Levinson, H. 1983. Analyzing transit travel time performance. Transportation Research Record 915: 1-6.

Levinson, H. 2001. Bus transit in the 21st century some perspectives and prospects. Transportation Research Record 1760: 42-46.

Levinson, H., S. Zimmerman, and J. Clinger. 2002. Bus rapid transit: An overview. Journal of Public Transportation 5(2):1-29.

Pahs, M., M. Rohden, D. Hampsten, S. Gallant, and R. Bertini. 2002. Door-to-door mobility: Evaluating a bus rapid transit communit transport concept. Journal of Public Transportation 5(2): 137-161.

Smith, N., and D. Hensher. 1998. The future of exclusive busways: The Brazilian experience. Transport Reviews 18(2): 131-152.

Strathman, J. 2002. Tri-Met's experience with automatic passenger counter and automatic vehicle location systems. Portland OR: Center for Urban Studies, Portland State University.

Strathman, J., K. Dueker, T. Kimpel, R. Gerhart, and S. Callas. 2002. Evaluation of transit operations: Data applications of Tri-Met's automated bus dispatching system. Transportation 29: 321-345.

Strathman, J. G., K. J. Dueker, T. J. Kimpel, R. L. Gerhart, K. Turner, P. Taylor, S. Callas, and D. Griffin. 2000. Service reliability impacts of computer-aided dispatching and automatic location technology: A Tri-Met case study. Transportation Quarterly 54(3): 85-102.

Strathman, J. G., and J. Hopper. 1993. Empirical analysis of bus transit on-time performance. Transportation Research Part A 27(2): 93-100.

Tétreault, P., and A. El-Geneidy. 2010. Estimating bus run times for new limitedstop service using archived AVL and APC data. Transportation Research Part A 44(6): 390-402.

Vandebona, U., and A. Richardson. 1985. The effects of fares-collection strategies on transit level of service. Transportation Research Record 1036: 79-87.

Vuchic, V. 2005. Transit operations and service scheduling. In Urban Transit: Operations, Planning and Economics, Hoboken, N.J.: John Wiley \& Sons. 


\section{About the Authors}

Ahmed El-Geneidy (ahmed.elgeneidy@mcgill.ca) is Assistant Professor in the School of Urban Planning at McGill University. His research interests include land use and transportation planning, transit operations and planning, travel behavior analysis including using motorized and non-motorized modes of transportation, and measurements of accessibility and mobility in urban contexts, with a special interest in transportation needs of disadvantaged populations. He received B.S. and M.S. degrees from the Department of Architectural Engineering at Alexandria University, Egypt, and continued his academic work at Portland State University, where he received a Graduate GIS Certificate and earned a Ph.D. in Urban Studies from the Nohad A. Toulan School of Urban Studies and Planning. After finishing his Ph.D., he moved to the Twin Cities to work as a post-doctoral research fellow at the University of Minnesota.

NithYA VIJAYAKUMAR (nithya.vijayakumar@mail.mcgill.ca) has a B.A. in Political Science and Geography from McGill University and currently is an MUP student and Graduate Research Assistant in the School of Urban Planning at McGill University. She developed a keen interest in bus operations and planning after working in Chennai and Bangalore, India, in 2007 and 2008. She currently is doing research on run time savings of articulated buses and factors that influence driving distance to commuter rail stations in Montréal. 